\title{
MIGRAÇÕES E MÍDIA DURANTE A PANDEMIA DE COVID-19: UMA ANÁLISE DE NOTÍCIAS PUBLICADAS NO JORNAL FOLHA DE SÃO PAULO
}

\author{
Migration and media during the COVID-19 pandemic: \\ an analysis of news articles published in the newspaper Folha de São Paulo
}

Julia Alves Brasil ${ }^{* * *}$

\begin{abstract}
Resumo. Este estudo objetivou analisar representações sociais de migração/ migrantes veiculadas pelo jornal Folha de São Paulo no ano de 2020, marcado pela pandemia de COVID-19. Foram analisadas 839 matérias, com o auxílio do software Iramuteq, a partir da Classificação Hierárquica Descendente. Identificaram-se seis classes lexicais, que abordaram as migrações tanto como uma questão política, envolvendo debates sobre aspectos econômicos e de segurança, quanto como uma experiência humana, a partir das vivências de migrantes em diferentes contextos. Os resultados permitiram evidenciar como, por um lado, a pandemia de COVID-19 aprofundou desigualdades pré-existentes e intensificou práticas discriminatórias dirigidas aos migrantes. E como, por outro lado, aliada a outros "eventos-chave", como eleições estadunidenses e protestos antirracistas, estimulou debates sobre preconceito e discriminação com relação a diferentes grupos minoritários, indicando que o caminho para a superação dessa crise e para a atenuação dos conflitos intergrupais por ela exacerbados passa pela inclusão de todos, inclusive migrantes.
\end{abstract}

Palavras-chave: migração; mídia; COVID-19; representações sociais.

Abstract. This study aimed at analysing social representations of migration/ migrants conveyed by the newspaper Folha de São Paulo in 2020, a year marked by the COVID-19 pandemic. We analysed 839 news articles with the software Iramuteq, by means of the Descending Hierarchical Classification. We identified six lexical clusters, which addressed migration both as a political matter, involving debates on economic and security issues, and as a human experience, based on the life experiences of migrants in different contexts. The results showed how, on the one hand, the COVID-19 pandemic deepened preexisting inequalities and intensified discriminatory practices against migrants. And how, on the other hand, combined with other "key events", such as the US election and the anti-racism protests, it stimulated debates about prejudice

Programa de Pós-Graduação em Psicologia da Universidade Federal do Espírito Santo (PPGP/ UFES). Vitória, ES, Brasil.

** Centro de Estudos de Comunicação e Sociedade (CECS) da Universidade do Minho, Portugal.

E-mail: juliaalvesbrasil@gmail.com. Orcid: https://orcid.org/0000-0003-0445-1207. 
and discrimination towards different minority groups, indicating that the path to overcome this crisis and to mitigate the intergroup conflicts exacerbated by it entails the inclusion of all, including migrants.

Keywords: migration; media; COVID-19; social representations.

\section{Introdução}

O ano de 2020 foi marcado pela pandemia de COVID-19 (Corona Virus Disease 2019), causada por um novo coronavírus denominado SARS-CoV-21. Fechamento de fronteiras e restrições de mobilidade dentro dos países e entre eles são algumas das medidas adotadas por líderes mundiais na tentativa de conter a disseminação do vírus, desafio que se mantém neste ano de 2021. Diante de tal contexto, diversos autores (e.g., Ardits, Laczko, 2020; Baeninger, 2020; Gamlen, 2020) têm refletido acerca dos possíveis impactos dessas restrições na mobilidade global e, particularmente, nos movimentos migratórios internacionais. Alguns governos têm se aproveitado do momento para intensificar imposições de restrições à migração que já estavam anteriormente em curso, como parte de um processo de securitização das migrações (e.g., McAuliffe, 2020), posto em prática, sobretudo, em países com políticas anti-imigração. No que diz respeito a solicitantes de refúgio e refugiados, em especial, a Agência da Organização das Nações Unidas/ONU para Refugiados (ACNUR, 2020) alertou para a importância de que o controle de fronteiras visando à proteção da saúde pública não contrariasse leis internacionais relativas a refúgio.

Tais preocupações com relação à situação de migrantes em diferentes contextos se fazem especialmente relevantes no momento atual, tendo em vista que a pandemia do novo coronavírus aprofunda desigualdades pré-existentes (Foley, Piper, 2020; Organização Internacional para as Migrações [OIM], 2020), afetando de forma mais acentuada indivíduos pertencentes a grupos usualmente mais vulneráveis (Foley, Piper, 2020; Jetten, 2020), como os migrantes. Adicionalmente, a pandemia cria um contexto que pode ou fomentar empatia e solidariedade ou produzir medo generalizado e aumentar a discriminação contra migrantes, dificultando, assim, a implementação de políticas de inclusão social (OIM, 2020). A fim de garantir a adoção de políticas de inclusão eficazes, um aspecto fundamental é compreender quais são os significados, crenças e atitudes que as pessoas partilham sobre determinados objetos sociais, por exemplo, migrantes. Tais significados partilhados sobre diferentes objetos auxiliam os indivíduos na compreensão do mundo, facilitam a sua comunicação e orientam as suas condutas, constituindo o que Moscovici (1961/2012) chamou de representações sociais.

Dois processos psicossociais estão envolvidos na construção de representações sociais: ancoragem e objetivação. A ancoragem pressupõe a incorporação de

1 Para mais informações sobre a pandemia de COVID-19, ver: <https://www.who.int/emergencies/ diseases/novel-coronavirus-2019>. 
elementos novos a um conjunto já conhecido de significados e categorias (Moscovici, 1961/2012); é um processo essencial para a realização de uma das principais funções das representações sociais: tornar familiar o não-familiar (Bonomo et al., 2020). Associada a este processo, está a objetivação, a qual permite tornar concretos alguns conceitos, transformando-os em algo mais palpável, por exemplo, ao substituir algumas ideias por imagens ou metáforas (Páez, Pérez, 2020). No ano de 2020, de forma similar ao ocorrido com relação a outras doenças infecciosas (e.g., Eicher, Bangerter, 2015), foi possível acompanhar o processo de elaboração de representações sociais acerca de um novo objeto social, a COVID-19. Assim, na tentativa de situar esse objeto não-familiar (Moscovici, 1961/2012), os indivíduos e grupos passaram a buscar "bodes expiatórios" para explicar a origem e a disseminação do vírus, reforçando estereótipos negativos dirigidos a esses diferentes "outros" (e.g., Eicher, Bangerter, 2015; Páez, Pérez, 2020), dentre eles os migrantes.

As mídias, como os jornais, por exemplo, desempenham um importante papel na (re)produção de representações sociais (Moscovici, 1961/2012; Rochira et al., 2020). No que concerne às migrações, os jornais recorrentemente retratam os migrantes como vítimas ou ameaças, associando-os à criminalidade e à violência (e.g., Batista, Bonomo, 2017; Chouliaraki, Georgiou, 2019; Eberl et al., 2018; Triandafyllidou, 2017). Assim, considerando a importância dos meios de comunicação na formação de discursos políticos e públicos sobre migração (Eberl et al., 2018; Rochira et al., 2020), tais narrativas podem contribuir para fomentar atitudes negativas e práticas de discriminação contra indivíduos migrantes. No entanto, os meios de comunicação também podem promover coberturas mais balanceadas sobre as migrações, apresentando perspectivas alternativas e mais inclusivas (e.g., Cogo, Badet, 2013; Heinderyckx, 2019; OIM, 2019; Triandafyllidou, 2017), questionando, portanto, estereótipos negativos usualmente atribuídos ao fenômeno migratório.

Com o intuito de promover a inclusão de todos, inclusive migrantes, líderes de diferentes países aprovaram, em 2018, o Pacto Global para Migração Segura, Ordenada e Regular (GCM, na sigla em inglês) (ONU, 2018), intimamente alinhado aos Objetivos de Desenvolvimento Sustentável (ODS) (ONU, 2015). O Brasil saiu do pacto em 2019, logo após a posse do presidente Jair Bolsonaro. Conforme discutem Mendes e Menezes (2019), essa saída representou um retrocesso na política migratória brasileira, visto que o país havia recentemente aprovado uma nova lei de migração (Lei de Migração no 13.445, 2017), finalmente alterando seus instrumentos jurídicos que datavam do período da Ditadura Militar e se baseavam em um paradigma de segurança nacional. Devido ao seu processo de colonização, o Brasil foi por muito tempo principalmente um país de imigração. Porém, sobretudo a partir da década de 1980, um contingente significativo de brasileiros começou a se mudar para o exterior (Cogo, 2018). Posteriormente, a 
partir de 2008, houve outro crescimento no número de imigrantes, especialmente a partir de 2010, com o terremoto no Haiti (Cogo, 2018), e, mais recentemente, após a crise social e econômica na Venezuela (Observatório das Migrações em São Paulo, 2020).

No que diz respeito aos estudos acerca da cobertura midiática sobre migração no Brasil, a maioria dos estudos recentes se refere a como grupos específicos são retratados nos meios de comunicação do país, com atenção especial aos haitianos e venezuelanos, sendo escassos estudos que investiguem como a migração e os migrantes, de forma geral, são abordados na mídia brasileira. Finalmente, no que concerne à pandemia de COVID-19, o Brasil tem apresentado uma das piores respostas do mundo a esse desafio, ao desconfiar da ciência e adotar estratégias que contribuíram para a disseminação do vírus, ao invés da sua contenção (Cf. Cepedisa, Conectas, 2021).

Tendo em vista essas breves considerações, este estudo teve como objetivo analisar as representações sociais sobre migração e migrantes veiculadas no ano de 2020 por um jornal brasileiro disponível on-line (Folha de São Paulo). Especificamente, objetivamos identificar as estruturas semânticas que organizam os conteúdos dessas representações sociais de migração/migrantes, bem como verificar possíveis relações entre os conteúdos de cada classe lexical analisada e determinadas variáveis contextuais de interesse, conforme descrevemos adiante.

\section{Estratégias Metodológicas}

O presente estudo se configurou como uma pesquisa documental, de caráter exploratório e descritivo, em que foram analisadas peças jornalísticas ${ }^{2}$ publicadas no jornal 'Folha de S.Paulo' ou 'Folha de São Paulo', conforme utilizamos neste trabalho. Tal jornal foi escolhido como fonte de dados devido à sua popularidade no Brasil, à sua cobertura diária e nacional e à sua disponibilidade de conteúdo integral em formato digital. O conjunto de dados analisados foi composto por 839 matérias publicadas neste jornal entre 01 de janeiro e 31 de dezembro de 2020, período intensamente marcado pela pandemia de COVID-19.

Para a coleta dos dados, foram utilizados os seguintes descritores: migrante/s, imigrante/s, emigrante/s, migração/migrações, imigração/imigrações, emigração/ emigrações. A busca foi realizada utilizando a opção 'tudo na Folha', com exceção das seções 'FotoFolha' e 'Painel do Leitor'. A partir desse procedimento, foram encontradas 1.583 matérias, excluindo-se aquelas repetidas. Desse total, 293 peças foram eliminadas pois incluíam o termo 'imigrantes' como referência à Rodovia dos Imigrantes, em São Paulo, ou o termo 'migração' para se referir à migração de animais de diferentes espécies ou, principalmente, no sentido de

\footnotetext{
2 Ressalta-se que, apesar de usarmos no texto as denominações "notícias" ou "matérias", incluímos em nosso corpus de dados peças jornalísticas classificadas como diferentes gêneros jornalísticos, por exemplo, reportagens, artigos de opinião, entre outros.
} 
mudanças/transferências em contextos diversos (por exemplo, "migração para serviços digitais"; "migração para trabalho remoto"). Em um segundo momento, a fim de evitar excessiva dispersão de conteúdo, foram excluídas 451 matérias que, apesar de conterem uma breve menção a migrantes/migrações no texto, não possuíam temas principais que fossem de alguma forma relacionados ao fenômeno migratório. Assim, apenas foram incluídas as 839 matérias cujos temas centrais se referiam, direta ou indiretamente, a: aspectos relativos às migrações; experiências de indivíduos migrantes; e/ou eventos específicos que envolviam migrantes ou discussões relativas à questão migratória.

O tratamento e a análise dos dados foram realizados com o auxílio do software Iramuteq (Interface de R pour les Analyses Multidimensionnelles de Textes et de Questionnaires) (Ratinaud, 2009), que é um programa empregado para análise estatística textual que é particularmente útil para analisar dados de veículos de comunicação, devido à sua capacidade de processar grandes conjuntos de dados e permitir a realização de diferentes tipos de análise (Camargo, Justo, 2013). Uma das análises realizadas pelo programa é a Classificação Hierárquica Descendente (CHD), a qual é baseada no método desenvolvido por Reinert (1990), segundo o qual o software decompõe o corpus inicial em segmentos de texto que são agrupados em classes, de acordo com as semelhanças entre os vocabulários utilizados. O programa realiza cálculos de qui-quadrado $\left(X^{2}\right)$ para verificar o grau de associação entre as formas linguísticas e as respectivas classes e produz um dendrograma que permite a visualização de tais classes. Dessa forma, quanto maior o $X^{2}$, maior a associação de determinado termo com aquela classe, conforme veremos nos resultados.

Na CHD também se pode analisar possíveis relações entre determinadas variáveis e as classes geradas. Neste estudo, usamos como variáveis: a) mês de publicação da matéria; b) seção do jornal; c) foco ou não na pandemia de COVID-19 - notícias que tinham como um dos temas principais a pandemia; notícias que não mencionavam a pandemia ou a mencionavam apenas de forma breve ao longo do texto; d) contexto da migração - nacional, envolvendo migração de brasileiros internamente ou migração de estrangeiros para o Brasil; internacional, focando na situação de brasileiros no exterior; internacional, abordando o fenômeno migratório de forma geral em diferentes países.

\section{Resultados e Discussão}

Optamos por conduzir a discussão dos resultados de forma conjunta com sua apresentação a fim de melhor explorar os diferentes conteúdos presentes nas classes lexicais analisadas. O corpus de dados teve 709.716 ocorrências de 40.352 formas distintas e os 839 textos iniciais foram desdobrados em 20.072 segmentos de texto. A partir da CHD, 17.934 segmentos de texto foram retidos, ou seja, $89,35 \%$ do material foi considerado na análise lexical. 
Figura 1

Dendrograma das classes estáveis - 20 termos com maior qui-quadrado

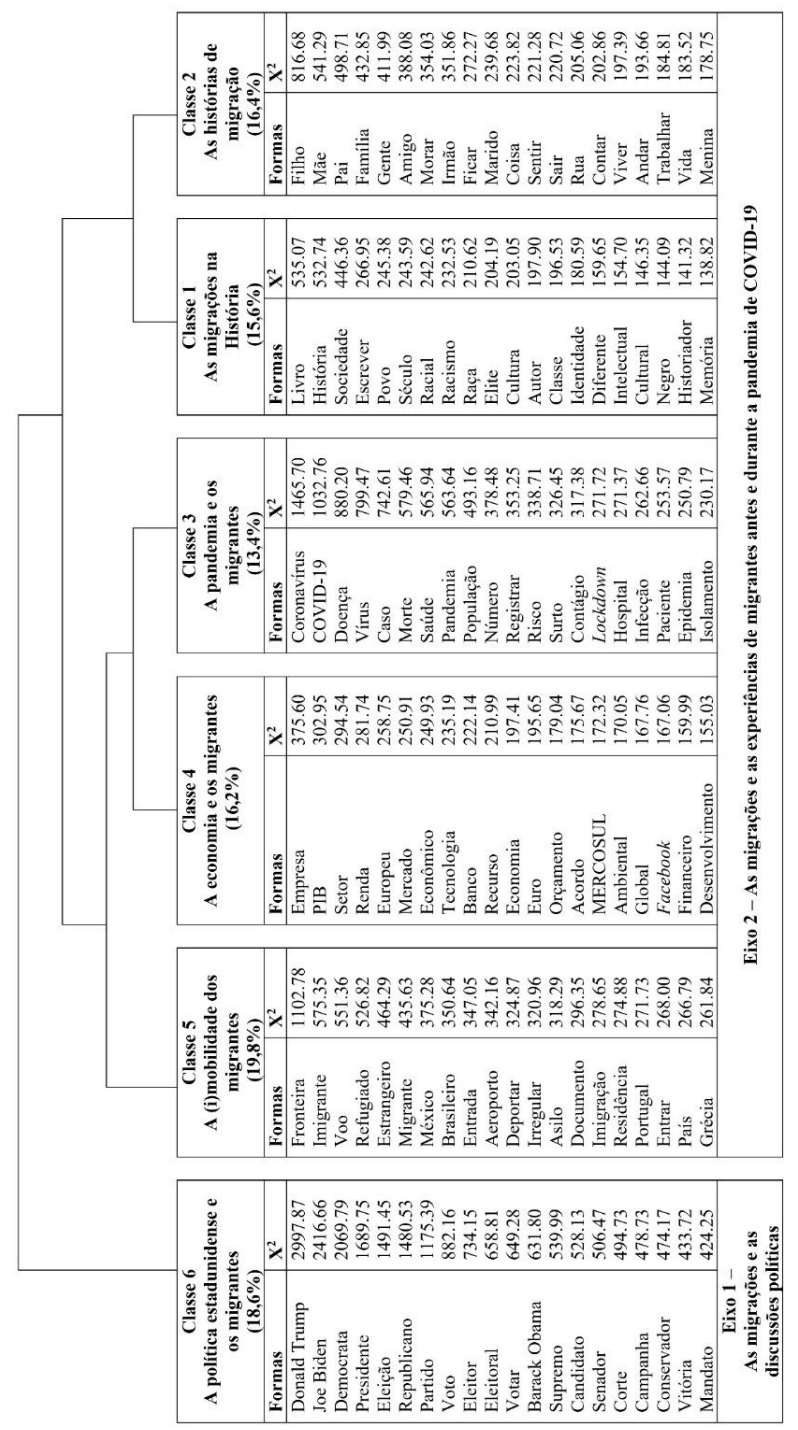

Fonte: Autora da presente pesquisa.

Conforme a Figura 1, a CHD dividiu o corpus em seis classes, organizadas a partir de dois eixos principais. O primeiro eixo, denominado 'As migrações e as discussões políticas', foi composto pela Classe 6; e, o segundo eixo, denominado 'As migrações e as experiências de migrantes antes e durante a pandemia de 
COVID-19', foi formado pelas demais classes (1, 2, 3, 4 e 5). Realizaremos a apresentação dos resultados seguindo a ordem numérica das classes.

A Classe 1 ('As migrações na História', com 15,6\% do corpus analisado) teve como variáveis mais significativas: contexto nacional; notícias sem foco na pandemia; e seção 'Ilustrada', a qual discute sobre arte, cultura, cinema, moda e música, seguida das seções 'Ilustríssima', que também discute sobre cultura, 'Ciência' e 'Quadro-Negro', que faz parte da seleção de colunas e blogs da Folha e aborda narrativas e reflexões a partir da perspectiva de pessoas negras.

Essa classe inclui segmentos de textos que discutem sobre preconceito e discriminação com relação a diferentes grupos minoritários, como os migrantes, em contextos distintos. Há destaque para conteúdos relativos a obras e autores que versam sobre a história do Brasil, mais especificamente sobre o período escravista e sobre o ideal de branqueamento da população por meio do estímulo da imigração europeia para o país (sobre essas discussões, ver, por exemplo, Cogo, 2018). Além disso, também inclui conteúdos relacionados a debates sobre o passado, o presente e o futuro do populismo nacionalista e as suas consequências para diferentes grupos, como o aumento dos discursos de ódio e da xenofobia. Tais conteúdos remetem também à necessidade de reconhecimento e respeito das diferentes culturas (ONU, 2015, 2018). Os segmentos de texto a seguir servem de ilustração:

"Como se fosse uma hidra, a desigualdade racial se recupera a cada golpe que sofre." Essa frase, extraída do livro "A Integração do Negro na Sociedade de Classes", publicado por Florestan Fernandes em 1965, condensa bem um aspecto aparentemente desconcertante da sociedade brasileira. Nossas desigualdades -a racial é uma de suas mais evidentes-se recompõem permanentemente, mesmo em meio a transformações estruturais profundas.

Ante a ideia da pureza racial que sustenta manifestações contra refugiados, o Estado deve, argumenta Emcke, garantir condições para a existência da diversidade. "Sinto-me menos vulnerável quando percebo que a sociedade em que vivo permite e sustenta estilos de vidas diferentes, crenças religiosas ou políticas distintas (...)".

A Classe 2 ('As histórias de migração', 16,4\%) se associa à Classe 1, formando um subconjunto dentro do Eixo 2. As variáveis mais significativamente associadas a essa classe foram: migrações no contexto nacional e no contexto internacional, focando nos brasileiros no exterior; mês de janeiro de 2020; e seções 'Esporte', 'F5', que aborda informações sobre celebridades e entretenimento, 'Babel Paulistana', que é um blog sobre eventos culturais promovidos por imigrantes em São Paulo, e 'Cotidiano', que cobre fatos do dia a dia das cidades brasileiras. Os segmentos de texto presentes nessa classe referem-se a histórias de vida de migrantes e suas famílias em diferentes contextos. Incluem histórias de brasileiros no exterior, por exemplo, nos Estados Unidos da América (EUA) e, com menor saliência, histórias de migrantes em geral em diferentes partes do mundo: 
Casado com uma brasileira e pai de dois filhos, $(. .)^{3}$ mora na Flórida e viaja a Governador Valadares de duas a três vezes ao ano, para visitar a mãe e os irmãos.

A classe agrega, ainda, histórias de pessoas que migraram para o Brasil há muitos anos, como a de alguns japoneses em São Paulo, bem como histórias de migrações mais recentes, a partir de relatos de sírios e venezuelanos que vieram para o país na tentativa de escapar de conflitos em seus países. Os relatos de venezuelanos evidenciam o caráter familiar dessa nova onda de migração venezuelana para o Brasil e a forte presença feminina, corroborando dados recentes no país (e.g., Observatório das Migrações em São Paulo, 2020):

(...) descreve o que considera sua maior conquista neste ano difícil: um celular para que possa ver seus filhos, de 12 e 4 anos, em movimento, mesmo que a distância. (...) ficaram na Venezuela com os avós depois que a mãe decidiu migrar para o Brasil em busca do sustento da família. Veio sozinha e achou mais seguro deixar as crianças com os avós até ter uma mínima estrutura e poder trazê-los para perto dela. Foi a decisão mais dura de sua vida. "Venezuelana, migrante, mãe solteira, cabeça da casa, com o coração entre dois países": é como (...) se define hoje, aos 41 anos.

A Classe 3 ('A pandemia e os migrantes', 13,4\%) teve como principais variáveis associadas: notícias com foco na pandemia; seção 'Equilíbrio e Saúde'; e meses abril e maio de 2020. Refere-se a conteúdos sobre a dispersão do vírus pelo mundo, incluindo informações sobre número de casos e mortes em diferentes países, bem como sobre as medidas necessárias para conter tal dispersão, como isolamento físico e uso de máscara. O segmento de texto abaixo ilustra esse conteúdo, a partir de uma notícia publicada no mês de abril de 2020:

Os EUA se tornaram o epicentro da Covid-19 no mundo. Nesta quarta, o país registrava mais de 600 mil casos confirmados do novo coronavírus e 24.429 mortes. É o país com o maior número de óbitos causados pela doença.

Inclui também segmentos que tematizam os impactos desiguais da COVID-19, afetando indivíduos pertencentes a grupos minoritários (Foley, Piper, 2020; Jetten, 2020), como os migrantes:

Os latinos são o grupo étnico com maior número de mortes devido ao novo coronavírus em Nova York, afirmou o prefeito da cidade, Bill de Blasio, nesta quarta-feira (8) [de abril], em entrevista coletiva.

Além disso, a classe também apresenta elementos referentes aos impactos da pandemia nas atitudes com relação à migração e aos migrantes (Gamlen, 2020; OIM, 2020), fortalecendo atitudes negativas e práticas discriminatórias com relação aos "outros" estrangeiros, por vezes considerados estranhos, com práticas anti-higiênicas e responsáveis pela origem do problema, conforme discutido em

3 Os nomes dos migrantes mencionados nas matérias analisadas foram suprimidos dos segmentos de texto citados. 
estudos anteriores no âmbito das representações sociais (e.g., Eicher, Bangerter, 2015; Páez, Pérez, 2020).

Maduro copia Trump, outro de seus adversários, ao chamar o patógeno que causa a Covid-19 de "vírus colombiano". O líder americano tem se referido ao coronavírus como "vírus chinês" ou "vírus de Wuhan", a cidade que registrou os primeiros casos da doença, o que já o rendeu acusações de racismo e xenofobia.

No início da pandemia do novo coronavírus, quando a doença ainda era mais notícia na China do que por aqui, sino-brasileiros relataram casos de racismo, frequentemente associados a estereótipos depreciativos que remontam aos do século 19, especialmente relativos à higiene.

Finalmente, alguns segmentos de texto presentes nessa classe ressaltam como a pandemia também tem evidenciado a importância dos migrantes em diferentes âmbitos da vida nos países, como na linha de frente nos cuidados com os pacientes com COVID-19 (Ardits, Laczko, 2020; Foley, Piper, 2020), como observado no seguinte trecho:

O discurso do premiê britânico, Boris Johnson, ao deixar o hospital depois de uma semana internado com Covid-19 (doença causada pelo novo coronavírus), mostra a importância da imigração para o sistema de saúde britânico. Os dois enfermeiros que "a cada segundo das noites estavam assistindo, pensando e cuidando" de Boris são estrangeiros.

Já a Classe 4 ('A economia e os migrantes', 16,2\%), intimamente relacionada à Classe 3, teve como principais variáveis categoriais: seção 'Mercado'; matérias com foco na pandemia; e contexto internacional geral. Essa classe aborda diversos aspectos relativos à economia, em termos gerais, e também no que tange aos impactos da pandemia nas economias de diferentes países e, consequentemente, na vida de migrantes. Vários segmentos de texto nessa classe se referiam à aprovação, pela União Europeia (UE), de um pacote para reconstrução das economias dos países pertencentes ao bloco após o fim da pandemia. As discussões sobre tal pacote envolveram a possibilidade de uso dos recursos comuns para pressionar países com condutas antidemocráticas, inclusive quanto à migração.

Ao aprovar o pacote de mais de 1,8 trilhão de euros (R\$ 11 trilhões, mais que o PIB anual do Brasil), o Conselho Europeu mobilizou recursos inéditos para um projeto geopolítico e econômico de transformar o bloco em liderança na economia verde e em digitalização.

Também tiveram destaque nessa classe as notícias sobre as negociações do acordo entre a UE e o Mercado Comum do Sul (MERCOSUL). Tal acordo foi objeto de discussões no contexto deste estudo visto que, para além de um capítulo comercial, envolve também um capítulo político, contendo temas como migração e direitos humanos. Ademais, outro aspecto presente nos segmentos texto foi quanto à atuação de entidades como o Banco Mundial e o Fundo Monetário Internacional (FMI) relativamente aos países pobres durante a pandemia, confirmando, novamente, os impactos desiguais da doença (Jetten, 2020): 
(...) o Banco Mundial e o FMI (Fundo Monetário Internacional), prometeram dar apoio a países pobres. Seus economistas alertaram sobre a necessidade de essas instituições liberarem ajuda financeira para evitar uma catástrofe humanitária e deter danos mais profundos na prosperidade global. Os mercados emergentes representam $60 \%$ da economia mundial, de acordo com uma avaliação do FMI. Um golpe nesses países tende a comprometer a economia de todo o planeta. Recursos enviados aos países pobres por trabalhadores migrantes -uma artéria vital nas finanças de países emergentes- também diminuíram.

Alguns segmentos de texto nessa classe enfatizaram, ainda, os impactos da pandemia na contratação de trabalhadores migrantes e a necessidade de reabertura de fronteiras para retomada da economia:

UE diz que retomada da economia precisa de fronteiras abertas a estrangeiros. Imigrantes e trabalhadores sazonais assumem postos de trabalho em setores essenciais. A pandemia de coronavírus mudou, ainda que temporariamente, a maneira com que países europeus lidam com trabalhadores estrangeiros, sazonais e imigrantes.

Por fim, a Classe 4 também agregou conteúdos relativos ao movimento Stop Hate for Profit ("Pare de dar lucro ao ódio"), que se configura como uma iniciativa que pede a diferentes anunciantes que boicotem plataformas de redes sociais, em especial o Facebook, para que essas empresas se responsabilizem e tomem medidas mais enérgicas quanto a discursos de ódio em mensagens publicadas nessas plataformas, a fim de proteger categorias sociais, como os migrantes, contra ataques:

A SAP, a empresa de tecnologia europeia mais valiosa, anunciou que não reiniciaria a publicidade até que veja "um compromisso significativo e que envolva ações concretas para combater a difusão de discurso de ódio e do racismo" por parte do Facebook.

Movimentos como esse são exemplos de possibilidades de ação de combate à discriminação e de promoção de sociedades mais inclusivas, em consonância com os ODS (ONU, 2015) e as metas do GCM (ONU, 2018).

Completando o Eixo 2, está a Classe 5 ('A (i)mobilidade dos migrantes', $19,8 \%$ ), a qual agrupa a maior parte do conteúdo analisado e teve como principais variáveis associadas: seção 'Mundo', que aborda fatos cotidianos relevantes no cenário internacional; migrações no contexto internacional, com foco em brasileiros no exterior; e meses janeiro e março de 2020. Essa classe agrupa menções a eventos diversos envolvendo migrantes em diferentes países, com destaque especial aos migrantes em situação irregular, incluindo impasses nas fronteiras e deportações, sobretudo no contexto da fronteira entre o México e os EUA. Destaca-se, ainda, a situação de solicitantes de asilo e refugiados na Europa e na América Latina. Os segmentos de texto a seguir ilustram diferentes conteúdos presentes nessa classe:

Em razão do aumento do número de brasileiros apreendidos na fronteira, os EUA adotaram outras medidas para desencorajar a imigração irregular. Desde a semana 
passada, brasileiros detidos na fronteira com o México poderão ser devolvidos ao país latino-americano, para aguardar a análise dos pedidos de asilo pelos EUA.

O Permaneça no México (MPP, na sigla em inglês) estipula que imigrantes sem documentos presos na fronteira com o México retornem ao país para esperar a avaliação de seus pedidos de asilo nos EUA pela justiça de imigração americana. O programa será suspenso imediatamente, de acordo com a decisão, e deverá ser possível a quem busca asilo aguardar em solo americano a tramitação do processo.

Uma criança morreu após ser resgatada do mar Egeu depois de um barco afundar nesta segunda (2 [de março]), na costa da ilha grega de Lesbos. Essa foi a primeira morte desde que a Turquia abriu suas fronteiras na semana passada para permitir que imigrantes destinados à União Europeia atravessem o país.

A menção a 'Portugal', entre os principais termos associados a essa classe, se deve à presença de diferentes notícias sublinhando aspectos positivos e negativos quanto à sua atuação com relação a migrantes. Por um lado, matérias sobre como Portugal pretende facilitar a concessão de nacionalidade a filhos de migrantes e a estrangeiros; além de notícias que elogiam as boas medidas adotadas pelo país no que diz respeito à pandemia, seguindo práticas sugeridas por diferentes entidades (ACNUR, 2020; OIM, 2020).

Com a pandemia, o governo de Portugal regularizou a situação de todos os imigrantes com pedidos de residência feitos até 18 de março, quando entrou em vigor o estado de emergência no país, e garantiu aos estrangeiros condições de acesso à saúde e aos programas de assistência financeira.

Por outro lado, notícias sobre a morte de um ucraniano em um aeroporto de Portugal no final de 2020, denunciando deficiências e apontando para a necessidade de revisão do seu sistema migratório:

A morte de um ucraniano no centro de detenção temporária do aeroporto de Lisboa, a popular "salinha da imigração" aonde são levados suspeitos de tentar entrar irregularmente no país, desencadeou uma série de denúncias de abusos por agentes do SEF (Serviço de Estrangeiros e Fronteiras).

Finalmente, também mereceu destaque nessa classe o caso de migrantes venezuelanos que ficaram semanas presos em uma ponte na fronteira entre o Brasil e o Peru devido a restrições impostas por estes governos em razão da pandemia. No entanto, conforme argumentação contida no segmento de texto a seguir, tal situação está em desacordo com as orientações do ACNUR (2020):

Em documento de março deste ano, o Acnur (agência da ONU para refugiados) reconheceu que os Estados têm a prerrogativa de restringir as fronteiras por razões de saúde pública, mas declarou que não devem deixar de proteger pessoas que pedem refúgio.

Compondo o Eixo 1, encontra-se a Classe 6 ('A política estadunidense e os migrantes', 18,6\%), que teve como principais variáveis categoriais: seção 'Mundo'; migrações em contexto internacional geral; notícias sem foco na pandemia; e mês de novembro de 2020. Como é possível observar a partir dos principais termos associados a essa classe (Figura 1), houve grande número de segmentos de texto 
envolvendo o ex-presidente dos EUA, Donald Trump, abordando, dentre outros aspectos, a sua forte atuação anti-imigração ao longo de todo o seu governo, a exemplo dos processos de separação entre crianças e seus pais em centros de detenção para migrantes.

Além disso, devido à ocorrência das eleições presidenciais nos EUA, em novembro de 2020, somada aos protestos antirracistas que ganharam as ruas do país e do mundo, diversas notícias giraram em torno das disputas entre as propostas das candidaturas de Trump e Joe Biden. De um lado, o candidato republicano, com discurso populista e xenofóbico, e, de outro, o candidato democrata que, junto da sua vice, Kamala Harris, representava uma possiblidade de mudança e maior valorização dos diferentes grupos que compõem a população estadunidense. Cumpre ressaltar que, ainda que não tenha figurado entre os 20 termos com maior qui-quadrado nessa classe, o nome 'Kamala Harris' foi a expressão com $25^{\circ}$ maior qui-quadrado ( $\left.\mathrm{X}^{2}: 353.41\right)$, visto que o corpus foi composto por diversas matérias sobre Harris, com foco na importância da sua eleição como forma de representatividade: uma mulher, negra e filha de migrantes.

Já outros segmentos de texto contidos nessa classe abordavam as disputas entre os candidatos à presidência para conquistar votos de latinos no país, como se observa neste trecho ampliado:

O presidente tem conduzido uma forte política anti-imigração, o que afasta parte dos eleitores latinos do Texas e do Arizona, que fazem fronteira com o México, mas seu discurso contra as ditaduras em Cuba e na Venezuela tem apelo entre latinos mais velhos e conservadores da Flórida - 54\% dos eleitores de origem cubana votaram no republicano em 2016. A retórica de Trump de que Biden é ligado à extrema esquerda e vai mergulhar os EUA no socialismo tem influência neste último grupo, apesar de o democrata ter uma trajetória política centrista.

A quantidade de notícias foi particularmente relevante no mês de novembro não apenas por ter sido a data da eleição, mas também devido ao questionamento que se seguiu à votação, período em que Trump se recusou a reconhecer os resultados das urnas e acionou a justiça a fim de reverter a disputa. Assim, essa classe inclui também conteúdos relativos à questão da continuidade do populismo e dos ideais pregados por Trump e pela extrema-direita, inclusive no que se refere às atitudes negativas com relação aos migrantes, visto que parte considerável da população ainda votou no presidente Trump e parece partilhar desses ideais (e.g., Mello, 2020).

De modo geral, os resultados reproduzem alguns elementos encontrados em estudos anteriores sobre a cobertura midiática em relação à migração e aos migrantes (e.g., Rochira et al., 2020). A migração é frequentemente representada nas notícias analisadas como uma questão política, sendo objeto de debates envolvendo aspectos econômicos, de segurança, entre outros (ver Eixo 1 da Figura 1); e representada também como uma experiência humana, a partir das vivências individuais de migrantes em diferentes contextos (ver Eixo 2 da Figura 1). 
Contudo, diferentemente de estudos conduzidos sobre o contexto europeu, nos quais houve uma forte ligação de migrantes à criminalidade no material analisado (e.g., Batista, Bonomo, 2017; Chouliaraki, Georgiou, 2019; Eberl et al., 2018), tal foco não foi encontrado neste estudo. Com exceção, entretanto, de matérias sobre assassinatos classificados como ataques terroristas, em que era mencionada a origem estrangeira dos agressores, por exemplo, em notícias sobre o ataque com faca ocorrido em Nice, na França, em outubro de 2020.

Além disso, assim como em estudos anteriores (e.g., Batista, Bonomo, 2017; Chouliaraki, Georgiou, 2019; Eberl et al., 2018; Rochira et al., 2020), as representações sociais de migrantes envolveram a sua objetivação (Moscovici, 1961/2012) como vítimas ou vilões, mas, em nosso caso, no contexto da pandemia de COVID-19. Como discutem Páez e Pérez (2020) acerca da elaboração de representações sociais sobre novas epidemias, o processo de ancoragem funciona também como um mecanismo para garantir a manutenção da autoestima positiva do próprio grupo, ancorando a doença em outros grupos, conforme observamos, por exemplo, em segmentos de texto que faziam referência ao "vírus chinês". Assim, estes "outros" passam a personificar o problema, por meio do processo de objetivação, associado à ancoragem (Páez, Pérez, 2020). E, dentre estes "outros", como vimos, estão os migrantes e refugiados, os quais, conforme critica Heinderyckx, "provaram ser os bodes expiatórios perfeitos para o flagelo do momento: crise econômica, desemprego, pobreza, criminalidade, terrorismo, ameaças à saúde (...)" (2019, p. 199, tradução nossa). Para além da sua objetivação como vilões quanto à origem e à transmissão da doença, também foi possível observar no corpus de dados analisado, sobretudo na Classe 3, que os migrantes foram objetivados como heróis - envolvidos na linha de frente dos cuidados aos pacientes com COVID-19 -, ou como vítimas - constituindo um grupo vulnerável tanto à infecção pelo vírus quanto aos efeitos sociais e econômicos provocados pela pandemia.

Vale notar, contudo, que, em geral, as reportagens analisadas, ao evocarem tais representações dos migrantes, também ofereciam questionamentos sobre elas, de forma a rechaçar discursos preconceituosos e homogeneizadores, fazendo um alerta sobre a necessidade de dar visibilidade tanto às consequências da pandemia para os migrantes quanto à contribuição deles no processo de enfrentamento da crise por ela gerada (Ardits, Laczko, 2020; Foley, Piper, 2020). Tais questionamentos, aliados também a reportagens que convocavam diferentes atores para discutir sobre aspectos relativos ao fenômeno migratório, inclusive os próprios migrantes, demonstram a presença de algumas boas práticas editoriais, conforme recomendações de pesquisadores da área (e.g., Cogo, Badet, 2013; Triandafyllidou, 2017). No entanto, ressalta-se que grande parte das peças jornalísticas que retratavam os migrantes como indivíduos e não apenas como um grupo, como é comum na cobertura midiática sobre migrações (Triandafyllidou, 2017), pertencia às seções "alternativas" do jornal, como colunas e blogs, e não 
tinha como foco a pandemia, como vimos no conteúdo nas classes 1 e 2. Ou seja, nessas seções houve mais espaço para as narrativas dos próprios migrantes, permitindo, como sugerem Heinderyckx (2019) e Triandafyllidou (2017), ir além das narrativas que usualmente possuem maior valor noticioso, as quais representam os migrantes apenas como ameaças ou vítimas, compartilhando, assim, histórias positivas de migração e refúgio. Porém, mesmo com a tentativa de fornecer uma perspectiva mais balanceada sobre as migrações, várias matérias falharam no que se refere ao uso adequado de termos relacionados às migrações. Por exemplo, em várias delas parecia haver uma confusão entre os termos 'migrante' e 'refugiado', os quais eram usados indiscriminadamente, como já alertado em publicações anteriores (e.g., OIM, 2019). Em algumas matérias houve, ainda, o uso de expressões como 'imigrante ilegal', o que está em desconformidade com boas práticas editoriais (e.g., Cogo, Badet, 2013; OIM, 2019).

Em suma, os resultados permitiram evidenciar como a existência de determinados eventos relevantes, como a pandemia de COVID-19 - além das eleições estadunidenses e dos protestos antirracistas ocorridos em diferentes países do mundo - podem influenciar a saliência de conteúdos específicos nas matérias (Rochira et al., 2020). Desse modo, tais acontecimentos se constituíram como "eventos-chave" que estimularam debates sobre preconceito e práticas discriminatórias dirigidas a migrantes e a demais indivíduos pertencentes a diferentes grupos sociais minoritários. Conforme discutido anteriormente, durante a pandemia de COVID-19, o processo de familiarização (Bonomo et al., 2020) desse novo objeto social fez com que estereótipos negativos com relação a diferentes categorias sociais, como os migrantes, fossem reforçados. Assim, dada a íntima relação entre representações e práticas sociais (Moscovici, 1961/2012), ao longo do ano de 2020, como foi possível notar nas matérias analisadas, a intensificação desses estereótipos negativos relacionados aos migrantes levou não apenas à ocorrência de novos episódios xenofóbicos (OIM, 2020), mas também a uma ampliação do processo de securitização das migrações (McAuliffe, 2020) em alguns países.

Por outro lado, tais acontecimentos também se configuraram como importantes para o reaquecimento das discussões sobre esses temas, levando diferentes autores (e.g., Dovidio et al., 2020; Greenaway, 2020) a afirmarem que a superação da pandemia de COVID-19 envolve a necessidade de desenvolvimento de um senso de identidade comum entre as pessoas, a partir da pertença a uma categoria social supraordenada (Dovidio et al., 2020) que inclua todos os setores da sociedade: humanos. Desse modo, apesar das incertezas quanto ao real impacto da pandemia de COVID-19 no futuro das migrações internacionais (e.g., Ardits, Laczko, 2020; Baeninger, 2020; Gamlen, 2020), o caminho para a superação dessa crise e para a atenuação dos conflitos intergrupais por ela acentuados parece passar pela solidariedade, pelo respeito e pela inclusão de todos (e.g., Dovidio et 
al., 2020; Greenaway, 2020). Como nos lembra Marinucci (2021), no editorial publicado este ano na presente revista, "não nos salvaremos sozinhos" (p. 12).

\section{Considerações Finais}

Neste estudo, investigamos as representações sociais de migração/migrantes veiculadas pelo jornal Folha de São Paulo no ano de 2020, um ano marcado pela pandemia de COVID-19. Os resultados nos permitiram analisar as múltiplas formas como os migrantes são retratados nesse veículo de comunicação, além de refletir sobre algumas consequências da pandemia com relação ao fenômeno migratório.

Entretanto, considerando a sua natureza exploratória e descritiva, bem como o desafio de estudar um fenômeno enquanto ele ainda está em curso, como é o caso da pandemia do novo coronavírus, o estudo teve algumas limitações. Primeiramente, selecionamos apenas um jornal brasileiro, logo, os resultados aqui encontrados não podem ser generalizados a toda a mídia jornalística do país. Em segundo lugar, optamos por realizar a busca no jornal apenas a partir de termos relativos às migrações e aos migrantes de forma geral. Portanto, não utilizamos como descritores de busca termos como 'refugiado/s', 'solicitante/s de asilo' e 'solicitante/s de refúgio', o que pode ter delimitado o escopo do corpus de dados, ainda que várias matérias selecionadas também abordassem a temática do refúgio. Além disso, centramos nossas análises no tratamento dos dados realizado com o auxílio do software Iramuteq. Apesar da diversidade de discussões propiciadas a partir desse tratamento, estudos futuros de cunho mais qualitativo podem ser realizados a fim de explorar com maior profundidade nuances que não foram apreendidas na análise que realizamos. Finalmente, estudos futuros também podem se beneficiar de uma abordagem comparativa com outros países, tendo em vista que é comum haver variações nas representações de migração/migrantes de acordo com diferentes contextos nacionais.

A cobertura midiática sobre migrações, sobretudo em períodos de crise como o atual, no contexto da pandemia de COVID-19, se constitui como um tópico multifacetado que possui múltiplos impactos na sociedade como um todo. Esperamos que o presente estudo tenha contribuído para enriquecer o conhecimento nas áreas de migração e mídia no Brasil e para fortalecer os debates sobre o fenômeno migratório, favorecendo a construção de sociedades mais sustentáveis e inclusivas.

\section{Referências bibliográficas}

ACNUR. Agência da ONU para Refugiados. Practical recommendations and good practice to address protection concerns in the context of the COVID-19 pandemic. 2020. Disponível em: <https://www.acnur.org/portugues/2020/04/28/covid-19acnur-da-recomendacoes-praticas-de-apoio-a-paises-europeus-para-reforcar-oacesso-a-refugio-e-recepcao-segura/> . Acesso em: 06.01.2021. 
ARDITS, Solon; LACZKO, Frank. Introduction - Migration policy in the age of immobility. Migration Policy Practice, v. X, n. 2, p. 2-7, 2020.

BAENINGER, Rosana. Migrações internacionais e a pandemia de Covid-19: mudanças na era da migração? In: BAENINGER, Rosana; VEDOVATO, Luís Renato; NANDY, Shailen (coords.). Migrações internacionais e a pandemia de Covid-19. Campinas: Núcleo de Estudos de População 'Elza Berquó' - NEPO/Unicamp, 2020, p. 211-220.

BATISTA, Roberta Rangel; BONOMO, Mariana. Representações sociais de imigração e imigrantes em jornais britânico, francês e alemão no ano 2012. Estudos e Pesquisas em Psicologia, v. 17, n. 2, p. 432-453, 2017.

BONOMO, Mariana et al. Familiarizando a não-familiaridade: alteridade e dimensão afetiva nas representações sociais de ciganos. Sociedade em Debate, v. 26, n. 3, p. 90-109, 2020.

CAMARGO, Brigido Viseu; JUSTO, Ana Maria. IRAMUTEQ: um software gratuito para análise de dados textuais. Temas em Psicologia, v. 21, n. 2, p. 513-518, 2013.

CEPEDISA - Centro de Pesquisas e Estudos de Direito Sanitário; CONECTAS - Conectas Direitos Humanos. Direitos na Pandemia: Mapeamento e Análise das Normas Jurídicas de Resposta à COVID-19 no Brasil. Boletim n. 10, 2021. Disponível em: <http://cepedisa.org.br/wp-content/uploads/2020/07/02boletimcovid_PT_06. pdf $>$. Acesso em: 30.05.2021.

CHOUlIARAKI, Lilie; GEORGIOU, Myria. The digital border: Mobility beyond territorial and symbolic divides. European Journal of Communication, v. 34, n. 6, p. 594-605, 2019.

COGO, Denise. O Haiti é Aqui: mídia, imigração haitiana e racismo no Brasil. Chasqui: Revista Latinoamericana de Comunicación, n. 139, p. 427-448, 2018.

COGO, Denise; BADET, Maria. Guia das Migrações Transnacionais e Diversidade Cultural para Comunicadores: Migrantes no Brasil. Bellaterra: Institut de la Comunicación-UAB/Instituto Humanitas - Unisinos, 2013.

DOVIDIO, John F.; IKIZER, Elif G.; KUNST, Jonas R.; LEVY, Aharon. Common Identity and Humanity. In: JETTEN, Jolanda; REICHER, Stephen D. S.; HASLAM, Alexander; CRUWYS, Tegan (orgs.). Together apart: The psychology of COVID-19. Londres: Sage Publications, 2020, p. 141-146.

EBERL, Jakob-Moritz; MELTZER, Christine E.; HEIDENREICH, Tobias; et al. The European media discourse on immigration and its effects: a literature review. Annals of the International Communication Association, v. 42, n. 3, p. 207-223, 2018.

EICHER, Véronique; BANGERTER, Adrian. Social representations of infectious diseases. In: SAMMUT, Gordon; ANDREOULI, Eleni; GASKELL, George; VALSINER, Jaan (eds.). The Cambridge handbook of social representations. Cambridge: Cambridge University Press, 2015, p. 385-396.

FOLEY, Laura; PIPER, Nicola. Covid-19 and women migrant workers: Impacts and implications. Genebra: OIM, 2020.

GAMLEN, Alan. Migration and mobility after the 2020 pandemic: The end of an age? 2020. Disponível em: <https://publications.iom.int/system/files/pdf/migrationand-mobility.pdf $>$. Acesso em: 08.01.2021. 
GREENAWAY, Katharine H. Group threat. In: JETTEN, Jolanda; REICHER, Stephen D. S.; HASLAM, Alexander; CRUWYS, Tegan (orgs.). Together apart: The psychology of COVID-19. Londres: Sage Publications, 2020, p. 61-67.

HEINDERYCKX, François. Conclusion. In: D'HAENENS, Leen; JORIS, Willem; HEINDERYCKX, François (eds.). Images of immigrants and refugees in Western Europe: Media representations, public opinion, and refugees' experiences. Leuven: Leuven University Press, 2019, p. 199-202.

JETTEN, Jolanda. Inequality. In: JETTEN, Jolanda; REICHER, Stephen D. S.; HASLAM, Alexander; CRUWYS, Tegan (orgs.). Together apart: The psychology of COVID-19. Londres: Sage Publications, 2020, p. 121-126.

LEI DE MIGRAÇÃO no 13.445, de 24 de maio de 2017. Institui a lei de migração. 2017. Disponível em: <http://www.planalto.gov.br/ccivil_03/_Ato2015-2018/2017/Lei/ L13445.htm>. Acesso em: 08.01.2021.

MARINUCCI, Roberto. Mobilidades, imobilidades e mobilizações em tempos de COVID-19. REMHU, Revista Interdisciplinar da Mobilidade Humana, v. 29, n. 61, p. 7-13, 2021.

MCAULIFFE, Marie. Immobility as the ultimate "migration disrupter": An initial analysis of COVID-19 impacts through the prism of securitization. Migration Research Series, n. 64, p. 1-13, 2020.

MELLO, Patrícia Campos. Onda populista de direita teve auge atrapalhado pela pandemia. Folha de S.Paulo, 21.12.2020. Disponível em: < https://www1.folha.uol. com.br/mundo/2020/12/onda-populista-de-direita-teve-auge-atrapalhado-pelapandemia.shtml>. Acesso em: 06.01.2021.

MENDES, José Sacchetta Ramos; MENEZES, Fábio Bensabath Bezerra de Menezes. Política migratória no Brasil de Jair Bolsonaro: "perigo estrangeiro" e retorno à ideologia de segurança nacional. Cadernos do CEAS: Revista Crítica de Humanidades, n. 247, p. 302-321, 2019.

MOSCOVICI, Serge. A psicanálise, sua imagem e seu público. Petrópolis: Vozes, 2012 (Obra originalmente publicada em 1961).

OBSERVATÓRIO DAS MIGRAÇÕES EM SÃO PAULO. Atlas temático - Migrações venezuelanas. Campinas: Núcleo de Estudos de População 'Elza Berquó' - NEPO/ Unicamp, 2020.

OIM - Organização Internacional para as Migrações. Countering xenophobia and stigma to foster social cohesion in the Covid-19 response and recovery. Genebra: OIM, 2020.

OIM - Organização Internacional para as Migrações. Glossary on Migration. Genebra: OIM, 2019.

ONU - Organização das Nações Unidas. Resolution adopted by the General Assembly on 25 September 2015. 2015. Disponível em: <http://www.un.org/ga/search/view_ doc.asp?symbol=A/RES/70/1\&Lang=E > . Acesso em: 06.01.2021.

ONU - Organização das Nações Unidas. Resolution adopted by the General Assembly on 19 December 2018. 2018. Disponível em: <https://www.un.org/en/development/ desa/population/migration/generalassembly/docs/globalcompact/A_RES_73_195. pdf >. Acesso em: 07.01.2021. 
PÁEZ, Darío; PÉREZ, Juan A. Social representations of COVID-19 (Representaciones sociales del COVID-19). International Journal of Social Psychology, v. 35. n. 3, p. 600-610, 2020.

RATINAUD, Pierre. IRAMUTEQ: Interface de R pour les Analyses Multidimensionnelles de Textes et de Questionnaires, 2009. [Software de computador].

REINERT, Max. Alceste une méthodologie d'analyse des données textuelles et une application: Aurelia De Gerard De Nerval. Bulletin de Méthodologie Sociologique, v. 26, n. 1, p. 24-54, 1990.

ROCHIRA, Alessia; AVDI, Evrinomy; KADIANAKI, Irini; POP, Alina; REDD, Rozlyn R.; SAMMUT, Gordon; SUERDEM, Ahmet. Immigration. In: MANNARINI, Terri; VELTRI, Giuseppe A.; SALVATORE, Sergio (eds.). Media and social representations of otherness: psycho-social-cultural implications. Cham: Springer, 2020, p. 39-59.

TRIANDAFYLLIDOU, Anna. Media Coverage on Migration: Promoting a Balanced Reporting. In: McAULIFFE, Marie; KLEIN-SOLOMON, Michele (orgs.). Ideas to Inform International Cooperation on Safe, Orderly and Regular Migration. Genebra: IOM, 2017, p. 1-10. 